\title{
Treatment of Stable Patients with Penetrating Chest Trauma Caused by Stab Wounds: Three vs six Hours Follow-up
}

\author{
Gimar Helena Facundo, Stella Isabel Martinez, Carlos Carvajal
}

\section{ABSTRACT}

Background: Treatment of stable patients with penetrating chest trauma caused by stab wounds is based on clinical observation and radiological follow-up. Classically, X-rays have been used at patient admittance and 6 hours after to detect hemothorax and pneumothorax not detected initially. Nevertheless, previous studies have explored the possibility of reducing follow-up time to 3 hours. This study compares 3 hours and 6 hours radiological follow-up to test the hypothesis that 3 hours follow-up is as safe interval than 6 hours for definitive management of stable patients with stab wounds in the chest.

Materials and methods: This is a prospective study conducted for 7 months from August 2010 through March 2011. Of the 162 eligible patients, 146 completed the protocol. Upon hospital admission all patients were clinically examined and evaluated with chest X-rays. Three hours and 6 hours follow-up X-rays after the trauma, in the Emergency Department, were taken of all patients radiologically assessed at admittance. We excluded patients with associated injuries requiring surgical intervention and we compared the findings of the two follow-up intervals.

Results: There were 225 stab wounds in the 146 patients evaluated. Average age was 29 years. One hundred and thirty-one patients had normal X-rays at admittance that did not change after 3 hours or 6 hours follow-ups. Fifteen patients presented hemothorax or pneumothorax in follow-up X-rays, 14 of them presented evident change in 3 hours X-ray follow-up. The only patient, whose lesion was evident in the 6 hours follow-up X-ray, but not the 3 hours follow-up X-ray, had a small asymptomatic pneumothorax, which did not require thoracic drainage.

Conclusion: No patients of 146 evaluated in our study developed traumatic pleuropulmonary injuries after 3 hours of follow-up that required pleural drainage or other intervention. Our results suggest that shortening the follow-up time from 6 to 3 hours for stable patients with chest stab wounds is safe, cost-effective and can help decongest emergency services.

Level of evidence: Therapeutic/care management study, level II.

Keywords: Thoracic injuries, Hemothorax, Pneumothorax.

How to cite this article: Facundo $\mathrm{GH}$, Martinez SI, Carvajal C. Treatment of Stable Patients with Penetrating Chest Trauma Caused by Stab Wounds: Three vs six Hours Follow-up. J Trauma Critical Care Emerg Surg 2013;2(3):101-105.

Source of support: Nil

Conflict of interest: None

\section{RESUMEN}

Antecedentes: El tratamiento de los pacientes estables con penetrante trauma en el pecho causado por heridas de arma blanca se basa en clínica observación y seguimiento radiológico. Clásicamente, los rayos $\mathrm{X}$ se han utilizado en la admisión del paciente y 6 horas después de detectar hemotórax y neumotórax no se detecta inicialmente. Sin embargo, estudios previos han explorado la posibilidad de reduciendo el tiempo de seguimiento de 3 horas. Este estudio compara 3 horas y 6 horas seguimiento radiológico para probar la hipótesis de que 3 horas de seguimiento es tan seguro intervalo de 6 horas para el definitivo manejo de pacientes estables con heridas de arma blanca en el pecho.

Materiales y métodos: Se trata de un estudio prospectivo realizado durante 7 meses a partir de agosto de 2010 hasta marzo de 2011. De los 162 pacientes elegibles, 146 completaron el protocolo. Al hospital de ingreso todos los pacientes fueron examinados clínicamente y evaluados con las radiografías de tórax. Tres horas y 6 horas rayos $X$ de seguimiento después del trauma, en el Servicio de Urgencias, se tomaron de todos los pacientes evaluados radiológicamente al ingreso. Se excluyeron los pacientes con lesiones asociadas que requieren intervención quirúrgica y se compararon los resultados de los dos intervalos de seguimiento.

Resultados: Se encontraron 225 heridas de arma blanca en los 146 pacientes evaluado. El promedio de edad fue de 29 años. Ciento treinta y un pacientes tenían radiografías normales al ingreso que hizo No cambie después de 3 horas o 6 horas de seguimiento. Quince pacientes hemotórax o neumotórax presentado en las radiografías de seguimiento, 14 de ellos presentó un cambio evidente en 3 horas de rayos $X$ de seguimiento. El único paciente, cuya lesión era evidente en las 6 horas seguimiento de rayos $X$, pero no las 3 horas de seguimiento de rayos $X$, tenía una pequeña neumotórax asintomática, que no requirió torácica de drenaje.

Conclusión: Ningún paciente de 146 evaluados en nuestro estudio lesiones traumáticas pleuropulmonares desarrollados después de 3 horas de seguimiento que requirió drenaje pleural u otra intervención. Nuestros resultados sugieren que la reducción del tiempo de seguimiento de 6-3 horas en los pacientes estables con heridas de arma blanca en el pecho es seguro, rentable y puede ayudar a descongestionar los servicios de emergencia.

Nivel de evidencia: Estudio de Manejo terapéutico/cuidado, nivel II.

Palabras claves: Lesiones torácicas, Hemotórax, Neumotórax.

\section{INTRODUCTION}

Traditionally, stable patients with penetrating chest trauma who have no other indications for surgery are observed in the emergency department. X-rays are taken upon admittance and 6 hours after admittance., ${ }^{1,2}$ The purpose of a second $\mathrm{X}$-ray is to detect late pneumothorax and hemothorax that were not observed upon admittance and that requires invasive treatment. ${ }^{3-7}$ 
Some authors reported that late hemothorax or pneumothorax occurs in $3 \%$ of these patients on average but may affect as many as $14 \% .{ }^{8,9}$ Nevertheless, subsequent studies have suggested that the monitoring period can be shortened to 3 hours without compromising the patient's safety. ${ }^{10-12}$

Our hypothesis in this study was that in stable patients with stab wounds in the thorax who has an initial normal chest X-ray, a 3 hours follow-up X-ray and clinical observation for this period after the trauma, are safe for determining definitive treatment.

\section{MATERIALS AND METHODS}

A 7 months prospective observational single cohort study of 162 patients with penetrating chest trauma caused by stab wound was conducted between August 2010 and March 2011.

\section{Inclusion Criteria}

- Stable patients (systolic blood pressure greater than or equal to $95 \mathrm{~mm} \mathrm{Hg}$ ) with thoracic stab wounds who did not require positive airway pressure and whose initial chest X-rays were normal or showed pneumothorax $<30 \%$.

- Stable patients with type I precordial stab wounds with normal pericardial ultrasound and normal initial chest $\mathrm{X}$-rays or with pneumothorax $<30 \%$ who did not require positive airway pressure.

- Stable patients with right thoracic- abdominal chest stab wounds without indications for surgery who did not require positive airway pressure and whose initial chest X-rays were normal or showed pneumothorax $<30 \%$.

- Stable patients with stab wounds in zone 1 of the neck who did not require positive airway pressure and whose initial chest X-rays were normal or showed pneumothorax $<30 \%$.

\section{Exclusion Criteria}

- Patients who presented dyspnea despite having less than $30 \%$ pneumothorax.

- Patients who became unstable during observation.

It is important to define the external anatomical boundaries of the thoracic region that we use in our institution's guidelines for the penetrating chest trauma management.

The thorax partially overlaps the thoracic-abdominal region, which is particularly important in trauma. In front, the pure thorax is located between the clavicles and the apex of the sternal notch and the fourth intercostal space. In back it is located between the seventh cervical vertebra and the lower edge of the scapulae. The upper edge of the thoracic-abdominal area is defined by the fourth intercostal space (nipple line in men) in front and the lower edge of the scapulae in back. It extends to the bottom edge of the ribs (Figs $1 \mathrm{~A}$ and $\mathrm{B}$ ). ${ }^{1}$

The precordium is defined as the front and left lateral area in the chest wall, located between the clavicles and the sternal notch and the lower edge of the ribs with lateral boundaries at the right midclavicular line and left midaxillary line (Figs $2 \mathrm{~A}$ and B). ${ }^{1}$

After initial patient assessment according to Advanced Trauma Life Support Program for Physicians, ${ }^{13}$ stab wounds are evaluated with chest X-rays if the patient's condition permits. Stable patients with no shortness of breath and wounds only in the chest are treated on the basis of the X-ray findings ${ }^{14}$ and clinical observation. ${ }^{15}$

If either hemothorax, greater than 30\% pneumothorax or hemopneumothorax are present, a chest tube is inserted (thoracostomy). Patients with less than $30 \%$ pneumothorax and those with initially normal X-rays continue under observation. A second X-ray is taken if new symptoms or signs develop during clinical observation or 6 hours after the

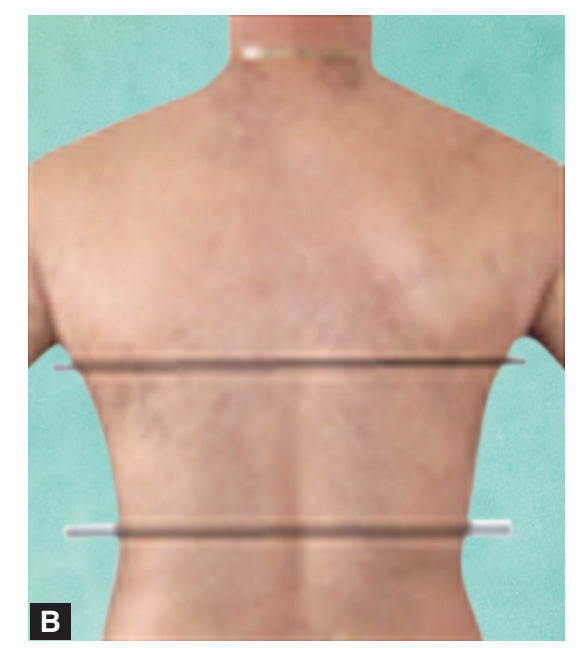

Figs 1A and B: Thoracic-abdominal area: (A) front side and (B) back side 


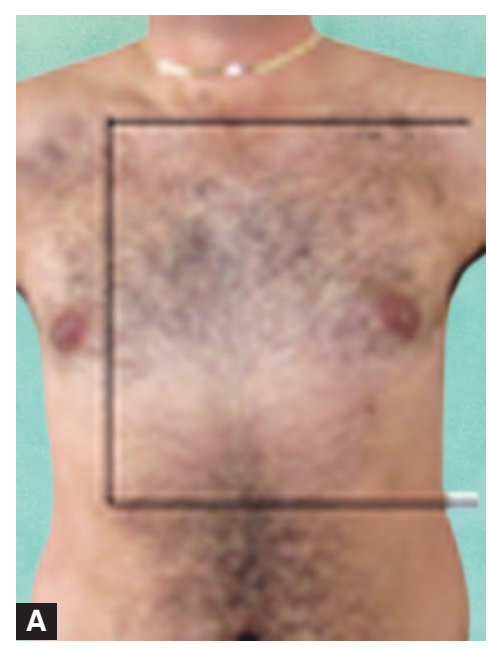

Figs 2A and B: Precordial area: $(A)$

trauma if no new symptoms or signs develop. A stable patient who has precordial stab wound type I and no clinical signs of cardiac tamponade should be evaluated for the presence of fluid in the pericardial sac. This check can be done by opening a pericardial window or by performing pericardial ultrasound. In case of left thoracic-abdominal stab wounds, diaphragmatic injury should be ruled out by direct or videoassisted observation (in surgery).

The method for quantify pneumothorax used for us was described by Rhea et al, taking three measurements of the distance separating the chest wall from the lung in the pleural cavity: one at the apex, one in the middle third, and one at the base. Values are added, divided by three, and evaluated according to a nomogram. An average separation of $2.7 \mathrm{~cm}$ indicates $30 \%$ pneumothorax (Fig. 3). ${ }^{16}$

\section{RESULTS}

Of the 162 eligible patients, 16 did not accept medical assessment after the initial X-ray and request for voluntary

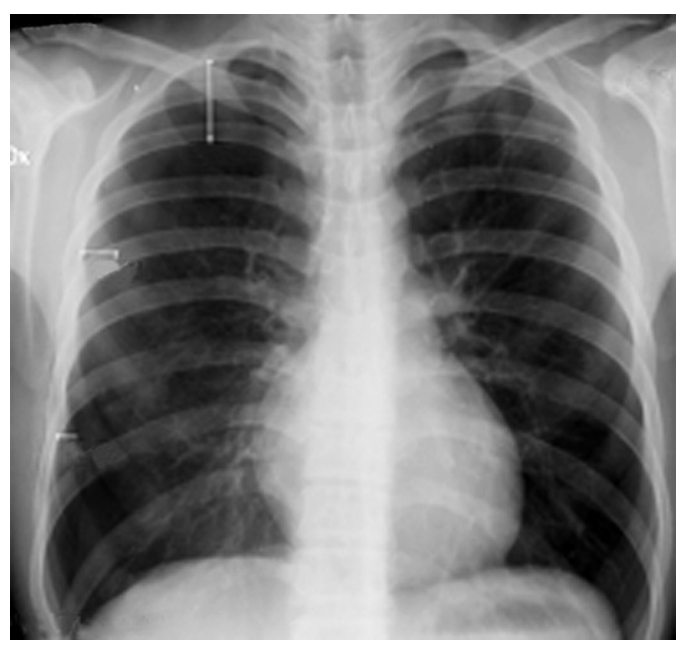

Fig. 3: PA chest $X$-ray with right pneumothorax. Interpleural distance is $3.6 \mathrm{~cm}$ at apex, $1.6 \mathrm{~cm}$ in the middle third and $1.5 \mathrm{~cm}$ at the base. Since the average value of $2.2 \mathrm{~cm}$ is less than $2.7 \mathrm{~cm}$, treatment is based on an expectation of less than 3

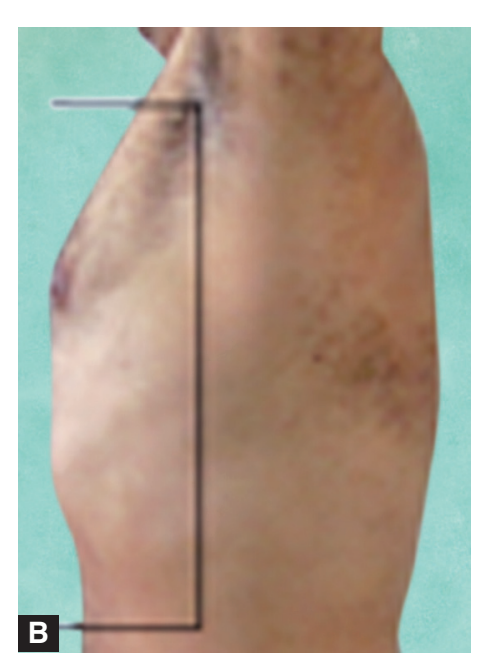

anterior view and (B) left side view

discharge, which left a total of 146 patients, 137 men and 9 women, in the study population.

The average age was 29.7 years. Ages ranged from 14 to 60 years. Of the 146 patients, 19 had previous thoracic surgery.

The 146 patients had 225 injuries (some patients had multiple injuries). Patient characteristics and wound location distribution are described in Table 1.

Average time between trauma and the first X-ray evaluations was 42 minutes, average time between trauma and the second X-ray was 3 hours and 28 minutes, and average time between trauma and the third X-ray was 6 hours and 58 minutes.

One hundred and thirty-one patients showed no changes between the first, second and third X-rays. They all completed the protocol without requiring further intervention (Flow Chart 1).

Flow Chart 1: Treatment flowchart for this study

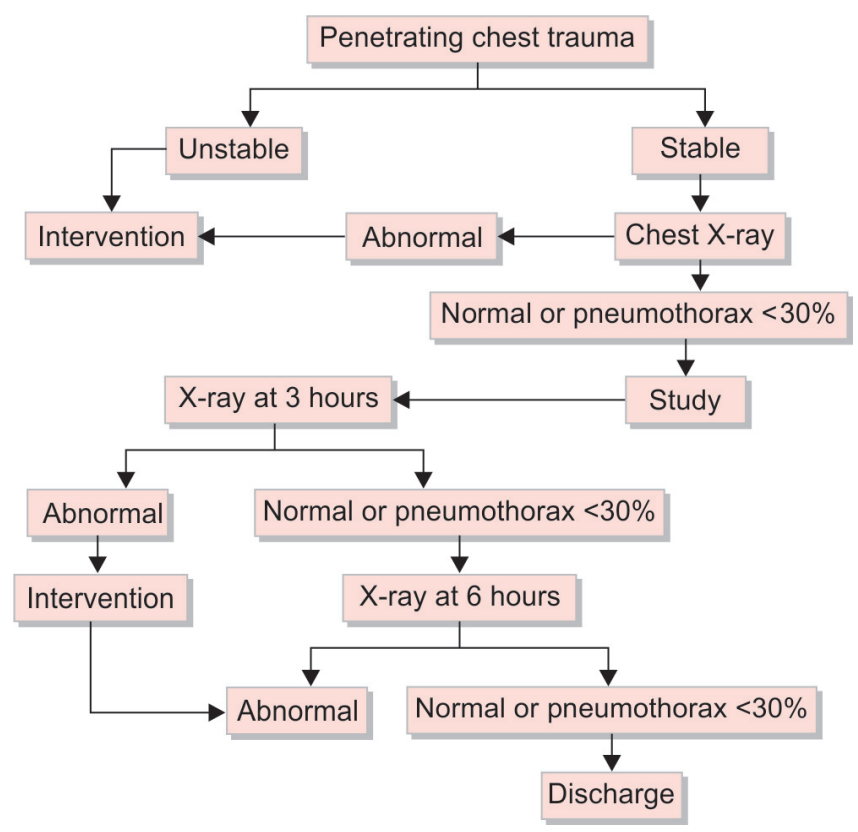


Table 1: The locations of some wounds involve more than one zone

Patient characteristics and distribution of wounds by location Male

Average age (years)

$29.7(14-60)$

History of chest surgery

$19(13 \%)$

$84(37 \%)$

Pure right thoracic wound

$65(29 \%)$

$21(9.3 \%)$

$24(10.7 \%)$

$17(7.6 \%)$

$6(2.6 \%)$

$5(2.2 \%)$

$4(1.6 \%)$

225

Only 15 patients showed radiographic changes in the follow-up X-rays, but not all required chest drain. Fourteen of them had changes in the 3 hours follow-up X-ray, but only 8 had chest drain. The remaining six showed less than 30\% pneumothorax and had no dyspnea. They remained stable in the 6 hours follow-up X-ray and were treated conservatively.

In one case were not changes in the second X-ray, but pneumothorax became evident in the third X-ray. Nevertheless, this patient did not require a chest drain because it was a less than $30 \%$ pneumothorax without dyspnea (Table 2).

\section{DISCUSSION}

An important issue for emergency department management of stable patients with penetrating chest traumas is the interval of time between X-rays for active detection of late hemothorax and pneumothorax. As other papers and articles discussing the effectiveness of diagnostic imaging such as $\mathrm{X}$-rays and CT-scans for patients with penetrating thoracic trauma have made clear, X-rays continue to be the diagnostic method of choice. ${ }^{17,18}$

In our series 16 patients requested voluntary discharges after their first X-ray. This type of situation occurs frequently in our hospital where we attend a great number of homeless people, drug addicts and patients with low socioeconomic levels. Consequently, the short time between the trauma and the first radiological evaluation found in our series is actually not the result of prehospitalization assessment procedures, but rather the result of the proximity of our hospital to scenes of trauma in a very poor area with high rates of violence in downtown Bogotá.

We found that, for stable patients with chest stab wounds who entered into our observation protocol and underwent radiographic follow-up, all significant radiological changes - those with clinical repercussions - were evident in the initial or second X-ray taken after an interval of 3 hours after the trauma.
Table 2: With one exception, all cases of hemothorax and pneumothorax were detected at 3 hours. The exception, detected at 6 hours, did not require chest drainage

Chest $X$-ray findings

\begin{tabular}{|l|c|c|c|}
\hline & Initial & 3 hours & 6 hours \\
\hline Pneumothorax $\leq 30 \%$ & 17 & 6 & 1 \\
\hline Pneumothorax $>30 \%$ & 0 & 5 & 0 \\
\hline Hemopneumothorax & 0 & 3 & 0 \\
\hline
\end{tabular}

Table 3: In total 450 patients have been assessed and only one lesion was detected in 6 hours follow-up X-rays

Studies comparing $X$-ray findings for penetrating chest trauma

at 3 and 6 hours

\begin{tabular}{|l|c|c|c|}
\hline Author & $n$ & 3 hours & 6 hours \\
\hline Kiev et al (1992) & 117 & 5 & 0 \\
\hline Shatz et al (2001) & 87 & 1 & 0 \\
\hline Seamon et al (2008) & 100 & 2 & 0 \\
\hline Current study & 146 & 14 & 1 \\
\hline Total & 450 & 22 & 1 \\
\hline
\end{tabular}

Radiological evaluations 6 hours after trauma did not detect any new clinically significant findings or changes. All chest drainage was performed based on the 3 hour follow-up X-rays.

Although intervals between radiological evaluations could not be timed exactly because of various emergency department factors which make it difficult to adhere strictly to schedules, all study patients completed at least 6 hours of clinical and radiological follow-up after their injuries.

Our findings support what has been previously reported in other studies. For stable patients with chest trauma caused by stab wounds, clinical monitoring plus a chest X-ray upon admission and a second X-ray 3 hours later is at least as safe as the current protocol of observation with an interval of 6 hours between the first and second X-rays (Table 3). ${ }^{10-12}$

We consider the findings of this study to be relevant. Shortening treatment time and patients' hospital stays, particularly time spent in high volume trauma services, without compromising patient safety, brings obvious cost and quality of care benefits to emergency departments.

\section{REFERENCES}

1. Livingston DH, Hauser CJ. Chest wall and lung in: Trauma, 6th ed. McGraw-Hill Medical: New York 2008:525-552.

2. Kerr T, Sood R, Buckman RF, Gelman J, Grosh J. Prospective trial of the 6 hours rule in stab wounds of the chest. Surgery, Gynecology and Obstetrics 1989;169:223-225.

3. Mowery NT, Gunter OL, Collier BR, et al. Practice management guidelines for management of hemothorax and occult pneumothorax. J Trauma 2011;70:510-518.

4. Ball CG, Kirkpatrick AW, Fox DL, et al. Are occult pneumothoraces truly occult or simply missed? J Trauma 2006; 60:294-299.

5. Ball CG, Kirkpatrick AW, Laupland K, et al. Factors related to the failure of radiographic recognition of occult posttraumatic pneumothoraces. Am J Surg 2005;189:541-546. 
6. Ball CG, Fitzpatrick AW, Laupland KB, et al. Incidence, risk factors, and outcomes for occult pneumothoraces in victims of major trauma. J Trauma 2005;59:917-925.

7. Muckart DJ. Delayed pneumothorax and haemothorax following observation for stab wounds of the chest. Injury 1985;16: 247-248.

8. Ordog GJ, Wasserberger J, Balasubramanium S, Shoemaker W. Asymptomatic stab wounds of the chest. J Trauma 1994;36: 680-684.

9. Mollberg NM, Wise SR, De Hoyos AL, Lin FJ, Merlotti G, Massad MG. Chest computed tomography for penetrating thoracic trauma after normal screening chest roentgenogram. Ann Thorac Surg 2012;93:1830-1835.

10. Kiev J, Kerstein MD. Role of three hour roentgenogram of the chest in penetrating and nonpenetrating injuries of the chest. Surgery, Gynecology and Obstetrics 1992;175(3):249-253.

11. Shatz DV, Pedraja J, Erbella J, Hameed M, Vail SJ. Efficacy of follow-up evaluation in penetrating thoracic injuries: 3 vs. 6 hours radiographs of the chest. J Emerg Med 2001;20:281-284.

12. Seamon M, Medina C. Follow-up after asymptomatic penetrating thoracic injury: 3 hours is enough. J Trauma 2008;65: 549-553.

13. American College of Surgeons Committee on Trauma. Thoracic trauma in: advanced trauma life support program for physicians, 8th ed. American College of Surgeons, Chicago 2008.

14. Currie G, Alluri R, Christie G, Legge J. Pneumothorax: an update. Postgrad Med J 2007;83:461-465.
15. Ammons MA, Moore EE, Rosen P. Role of the observation unit in the management of thoracic trauma. J Emerg Med 1986;4: 279-282.

16. Rhea JT, DeLuca SA, Green RA. Determining the size of pneumothorax in the upright patient. Radiology 1982;144: 733-736.

17. Magnotti L, Weinberg JA, Schroeppel TJ, et al. Initial chest CT obviates the need for repeat chest radiograph after penetrating thoracic trauma. The American Surgeon 2007;73(6):569-573.

18. Plurad D, Green D, Demetriades D, Rhee P. The increasing use of chest computed tomography for trauma: is it being overutilized? J Trauma 2007;62:631-635.

\section{ABOUT THE AUTHORS}

\section{Gimar Helena Facundo}

Surgeon, Department of Surgery, Hospital Santa Clara, Colombia

\section{Stella Isabel Martinez}

Thoracic Surgeon, Department of Surgery, Hospital Santa Clara Colombia

\section{Carlos Carvajal (Corresponding Author)}

Thoracic Surgeon, Department of Surgery, Hospital Santa Clara Colombia, e-mail: nechito1@hotmail.com 